\title{
КОМПЛЕКСНОЕ НЕЙРООРТОПЕДИЧЕСКОЕ ЛЕЧЕНИЕ ПАЦИЕНТОВ СО СПАСТИЧЕСКИМИ ФОРМАМИ ДЕТСКОГО ЦЕРЕБРАЛЬНОГО ПАРАЛИЧА В УСЛОВИЯХ МНОГОПРОФИЛЬНОГО ЦЕНТРА
}

\author{
*Жердев К.В., Челпаченко О.Б., Мамедьяров А.М. \\ ФГБУ "Научный Центр здоровья детей" РАМН, Москва
}

$\mathbf{H}$ ейроортопедические аспекты лечения детей с ДЦП включает хирургическую ортопедию, функциональную нейрохирургию и ортезирование. Патогенез двигательных нарушений в онтогенезе ребенка с ДЦП представляется следующим образом: перинатальное поражение головного мозга, нарушение редукции врождённых рефлексов, нарушение мышечного тонуса и патологические установки конечностей. При развитии вторичных контрактур суставов и вторичных деформаций скелета - эффективно воздействовать на данных этапах заболевания возможно только путем ортопедической хирургии. Фармакотерапия, функциональное ортопедическое лечение и ортезирование могут применяется на всех этапах развития двигательных нарушений при ДЦП. Препараты ботулотоксина типа А применяются от момента появления мышечного гипертонуса до патологической (постуральной) установки конечностей. К ортопедической хирургии мы прибегаем при наличии уже сформировавшихся вторичных контрактур суставов и деформаций скелета.

Функциональная нейрохирургия захватывает интервал между нарушением мышечного тонуса до формирования вторичных деформаций скелета. Функциональные нейрохирургические операции на современном этапе представлены 2-мя основными группами: это - деструктивные и нейромодулирующие операции. К деструктивным операциям относятся дорсальная селективная ризотомия и селективная деструкция глубинных структур головного мозга. Самой популярной в настоящее время нейромодулирующей операцией является имплантация помпы с целью интратекальной баклофенотерапии. Остальные функциональные нейрохирургические опера*e-mail: drzherdev@mail.ru ции уже являются пережитками прошлого это тотальная ризотомия, миелотомия, хроническая эпидуральная электростимуляция, и применяются крайне редко.

Итак - первая группа операций - дорсальные селективные ризотомии, целью которых является - ограничить афферентный поток сегментарных тонических рефлексов за счет пересечения фасцикул дорсальных корешков вовлеченного сегмента на основании результатов интраоперационного нейрофизиологического мониторинга. К преимуществам данного метода относятся: одномоментное селективное снятие патологического мышечного тонуса; необратимый эффект; снижение потребности в фармакотерапии; создание условий для ортезирования; снижение потребности в ортопедической хирургии.

Основные этапы этой операции: осуществляется доступ к содержимому дурального мешка, вскрывается паутинная оболочка, выделяется целевой корешок, разделяется на фасцикулы, далее производится их поочередная электростимуляция и идентификация, необходимые фасцикулы - пересекаются (под контролем интраоперационного нейрофизиологического мониторинга). Наряду с преимуществами данной операции, имеются также и существенные недостатки: эффект - необратимый (любая техническая погрешность это последствие на всю жизнь); оптимальный возраст - от 2 до 5 лет (в этом возрасте трудно предугадать сценарий двигательного развития в этом возрастном промежутке, недаром европейские нейроортопеды называют его "нежным" возрастом; частые расстройства чувствительности, в т.ч. со стороны тазовых органов; послеоперационные осложнения связанные с особенностями хирургичес- 
кого доступа (ликворея, эпидуриты, нейропатический болевой синдром, вялые парезы, посламинэктомические деформации позвоночника, и др. Учитывая наличие таких существенных недостатков - показания к данной операции представляются весьма ограниченными.

Нейромодуляционная нейрохирургия направлена на обеспечение интратекального постоянного введения баклофена ("имплантация баклофеновой помпы"). Механизм действия баклофена и других антиспастических препаратов давно известен. Преимуществами данного вида нейрохирургических операций являются: снижение дозировки антиспастического препарата (в сравнении с пероральным приемом), нивелирование побочных эффектов препарата (связано со снижением эффективной дозировки), облегчение ухода за пациентом, регресс болевого синдрома, облегчение ортезирования (благодаря коррекции патологической установки конечности, обусловленной спастикой), эффект - обратимый (в случае, если при динамическом наблюдении отмечается преобладание "нежелательных" эффектов над необходимыми). На целевом уровне устанавливается интратекальный (субдуральный) оросительный катетер, и под кожу имплантируется своеобразный насос (помпа), который предварительно заполняется баклофеном. Однако имеется и ряд существенных недостатков, это: необходимость 1 раз в 1,5-4 мес. - "заправлять" помпу; эффект зависит от длительности применения помпы (т.е. для поддержание эффекта необходимо непрерывное введение препарата); высокая стоимость самой помпы и препарата; высокий риск миграции катетера (к которой может привести любое неосторожное движение); постоянное нахождение инородного тела в позвоночном канале; частые эпизоды непроходимости катетера; общехирургические осложнения; влияние на помпу окружающих физических факторов (электрическое и магнитное поля, работа мобильных телефонов, которые могут привести к сбою работы помпы).

Наряду с большим количеством классифи- каций ДЦП, достаточно распространенной является классификация А. Феррари, который сам является врачом-неврологом, но его классификация спастической тетраплегии и диплегии, заинтересовала нас - ортопедов своей наглядностью и возможностью прогнозировать двигательное развитие ребенка.

Тетраплегия была классифицирована по способности противостоять гравитации: апостуральная форма, монопостуральная форма, "антигравитационная защита с горизонтальным корпусом", "антигравитационная защита с вертикальным корпусом".

Наиболее частой формой, согласно литературным данным, более 65\% детей с ДЦП составляют дети со спастической диплегией, которые подразделены по стереотипу ходьбы. Это - самый важный для ортопедов момент. Поскольку каждый ребенок с ДЦП вырабатывает свою собственную стратегию ходьбы, которую не нужно "ломать". Не нужно пытаться нормализовать (или стандартизировать) имеющийся двигательный паттерн. Это может привести к полной утрате способности вертикального передвижения. Все старания нейроортопеда должны сводиться к правильному распознанию двигательного стереотипа и увеличению функциональных возможностей пациента в его пределах. Выделяются 4 формы диплегии: пропульсивная форма, "узкая юбка", "канатоходец", "бесстрашные". Также необходимо отметить один из важных моментов нейроортопедии, что пациентам 3- и 4-ой формы не рекомендуется выполнять артродезирующие операции на стопах, поскольку без этого "раскачивания" они не ориентируются в пространстве, и велик шанс - лишить ребенка способности вертикального передвижения. С другой стороны - эти группы больных - любят ходить и ходят много, поэтому им нужны стабильные ТБС, которые в случае подвывиха требуется стабилизировать посредством операций на костных структурах.

Ортопедическое лечение традиционно делится на оперативное и консервативное. Оперативное ортопедическое лечение делится на следующие подгруппы: сухожильно-мышеч- 
ные, костные периферическая невротомия, комбинированные вмешательства. Необходимо также отметить, что в нейроортопедии, в отличие от классической ортопедии, все большее распространение получают, т.н. симультанные многокомпонентные операции, выполняемые в один наркоз, с целью максимального сокращения сроков послеоперационной иммобилизации для предупреждения потери уже сформированных навыков у ребенка с ДЦП.
Таким образом, основным критерием эффективности нейроортопедического лечения является: "Приобрел ли пациент более устойчивую позу и возможность движения в сравнении с естественным течением заболевания?" Для ее приобретения и поддержания необходима большая работа большого количества узких специалистов: ортопед, невролог, врач ЛФК, физиотерапевт, логопед, дефектолог, психолог, ЛОР, офтальмолог, ортопед, диетолог, нейрохирург и многие другие.

\title{
SUMMARY
}

\section{COMPLEX NEUROOTHOPEDICAL TREATMENT OF PATIENTS WITH SPASTIC FORMS OF CEREBRAL PALSY IN A MULTIDISCIPLINARY CENTER}

\author{
Zherdev K., Chelpachenko O., Mamediyarov A. \\ Scientific Center of Children's Health of the Russian Academy of Medical Sciences, Moscow
}

Neuroorthopedical aspects of the treatment of children with cerebral palsy include orthopedic surgery, neurosurgery and functional orthotics. The primary efficacy neuroorthopedic treatment is the acquisition of a child with cerebral palsy more stable posture compared with the natural course of the disease and the prevention of loss of already formed skills in a child with cerebral palsy.

\section{XÜLASə}

\section{ÇOXPROFILLI MӘRKəZ ŞӘRAITINDə UŞAQ SEREBRAL İFLICININ SPASTIK FORMASI İLO PASİYENTLORIN KOMPLEKS NEYROORTOPEDİK MÜALICCOSI}

\author{
Jerdev K.V.,Çelpaçenko O.B., Məmmədyarov O.B. \\ Rusiya Tibb Elmlari Akademiyasının «Uşaqların sağlamlı̆̆ elmi mərkəzi», Moskva
}

Uşaq serebral iflicinin müalicəsinin neyroortopedik aspektləri özündə ortopedik cərrahiyyə, neyrocərrahiyyə və ortezləşdirməni birləşdirir. Neyroortopedik müalicənin effektivliyinin əsas meyarı xəstənin əvvəlki vəziyyəti ilə müqayisədə onun daha dayanıqlı poza ala bilməsi və ya hərəki aktivliyinin mümkün olmasıdır. 